\title{
Visual function improvement using photocromic and selective blue-violet light filtering spectacle lenses in patients affected by retinal diseases
}

L. Colombo ${ }^{1 *}$, E. Melardi ${ }^{1}$, P. Ferri ${ }^{1}$, G. Montesano ${ }^{1}$, S. Samir Attaalla ${ }^{1}$, F. Patelli ${ }^{1}$, S. De Cillà², G. Savaresi ${ }^{3}$ and L. Rossetti ${ }^{1}$

\begin{abstract}
Background: To evaluate functional visual parameters using photocromic and selective blue-violet light filtering spectacle lenses in patients affected by central or peripheral scotoma due to retinal diseases.

Sixty patients were enrolled in this study: 30 patients affected by central scotoma, group 1, and 30 affected by peripheral scotoma, group 2.

Black on White Best Corrected Visual Acuity (BW-BCVA), White on Black Best Corrected Visual Acuity (WB-BCVA),

Mars Contrast Sensitivity (CS) and a Glare Test (GT) were performed to all patients.

Test results with blue-violet filter, a short-pass yellow filter and with no filters were compared.

Results: All scores from test results increased significantly with blue-violet filters for all patients.

The mean BW-BCVA increased from $0.30 \pm 0.20$ to $0.36 \pm 0.21$ decimals in group 1 and from $0.44 \pm 0.22$ to $0.51 \pm 0$. 23 decimals in group 2 (Mean \pm SD, $p<0.0001$ in both cases).

The mean WB-BCVA increased from $0.31 \pm 0.19$ to $0.38 \pm 0.23$ decimals in group 1 and from $0.46 \pm 0.20$ to $0.56 \pm 0$. 22 decimals in group 2 (Mean $\pm \mathrm{SD}, p<0.0001$ in both cases).

The letter count for the CS test increased from $26.7 \pm 7.9$ to $30.06 \pm 7.8$ in group 1 (Mean $\pm S D, p=0.0005$ ) and from $31.5 \pm 7.6$ to $33.72 \pm 7.3$ in group 2 (Mean $\pm \mathrm{SD}, p=0.031$ ).

GT was significantly reduced: the letter count increased from $20.93 \pm 5.42$ to $22.82 \pm 4.93$ in group 1 (Mean $\pm S D$, $p<0.0001$ ) and from $24.15 \pm 5.5$ to $25.97 \pm 4.7$ in group 2 (Mean \pm SD, $p<0.0001$ ).

Higher scores were recorded with the Blue filter compared to Yellow filter in all tests $(p<0.05)$.

No significant differences in any test results could be detected between the Yellow filter and the No filter condition.

Conclusions: The use of a combination of photocromic lens with a selective blue-violet light filter showed functional benefit in all evaluated patients.
\end{abstract}

Keywords: Blue light, Retinitis pigmentosa, AMD, Glare, Led light, Contrast sensitivity

\footnotetext{
* Correspondence: leonardo.colombo.82@gmail.com

'Department of Ophthalmology, San Paolo Hospital, University of Milan,

Milan, Italy

Full list of author information is available at the end of the article
} 


\section{Background}

Possible harmful effects of blue light have been known for half a century and linked to photochemical damage to retinal tissue and $\operatorname{RPE}[1,2]$.

More specifically, some studies showed that, while longer blue wavelengths of the visible spectrum (465-495) are essential for circadian rhythm and a normal visual function [3-5], blue-violet light could cause an oxygendependent retinal injury acting on specific chromophores (by-products of visual cycle) $[6,7]$.

The chromophore A2E (N-retinylidene-N-retinylethanolamine) is considered the most important target molecule. Under blue-violet light exposure conditions (400$440 \mathrm{~nm}$ ), this chemical seems to induce the production of reactive oxygen species and to initiate the activity of cysteine-dependent proteases, ultimately leading to apoptotis and cell death [6, 8-14].

One of the main known sources of blue light is the sunlight (25-35\% of the emitted spectrum), but an increasing contribution from indoor illumination has been recorded in the last 10 years. The widespread commercialization of high brightness light-emitting diodes (LEDs) have strongly changed indoor daily illumination [15]. In addition, white-light LED (the most common type of LED) have became the most important technology for smartphone screens [16], tablet backlighted displays and other commonly used devices.

A significant part of a LED-emission spectrum peaks at $450 \mathrm{~nm}$, thus within the wavelength range of blue light.

Shorter wavelength blue light has been reported to show a pivotal role in glare disability due to direct or reflected bright light and many attempts have been made to face this concern with intraocular or spectacle bluelight-filtering lenses.

Based on the results of Sahel and coworkers' on the phototoxic action of blue light on human RPE cells [17], some optical brands have produced increasingly specific blue-light-filtering spectacle lenses.

We tested the commercially available TRANSITION $X$ TRACTIVE ${ }^{\circ}$ plus CRIZAL PREVENCIA ${ }^{\bullet}$ (Essilor, France) spectacle lenses. The purpose of our study was to investigate whether people with ocular chronic disease characterized by either central or peripheral scotoma could benefit from their use, in terms of visual acuity, contrast sensitivity and glare.

\section{Methods}

We recruited 60 consecutive patients from the San Paolo Hospital Eye Clinic in Milan, 30 with central scotoma (within the 5 central degrees from the fovea) and 30 with peripheral scotoma (outside the 5 central degrees from the fovea). Each patient underwent a full ophthalmologic examination. Specific functional tests were performed: Black on White Best Corrected Visual Acuity (BW-BCVA), White on Black Best Corrected Visual Acuity (WB-BCVA), Mars Contrast Sensitivity (CS) and a Glare Test (GT). BCVA scores were reported in decimals, while Contrast Sensitivity and Glare Test results were expressed as number of letters correctly identified by the patient. Except for the GT, all other tests were performed with standard charts (Snellen for BCVAs and Mars for CS). Al evaluations were performed monocularly. To avoid letter memorization we used different charts when testing with or without the filters, both for Snellen and Mars charts. The GT was performed using the testing procedure offered by the MonPack 3 device (Metrovision, Lille, FR): briefly, the test was performed at $1 \mathrm{~m}$ distance with $\mathrm{a}+1.00$ spherical added to the best correction for distance; a letter chart was displayed on the screen, with letters at increasing distance form a bright light source directed toward the patient; the number of letters recognized by the patient was then reported.

On each subject, we performed all the tests with and without the application of blue-violet light filtering lenses (TRANSITION X-TRACTIVE ${ }^{\bullet}$ plus CRIZAL PRE$V E N C I A^{\circ}$, Essilor, France). Filter lenses come in 3 different colors (grey, brown and green) and, according to manufacturer instructions, the color selection was based on the individual subject preference in terms of visual comfort. These filtering lenses have two technologies: Transition Xtractive and Crizal Prevencia. The former is responsible for the photocromic effect. When activated, these photopigment dyes are able to filter $88-95 \%$ of light up to $430 \mathrm{~nm}$. The latter is an antireflective coating providing protection against both UV and Blue-Violet light in the backside and frontside of the lens, filtering up to $20 \%$ of the blue-violet light.

All tests with blue-violet filters were performed after the activation of the lens by means of a UV light.

In order to compare the effect of the blue-violet filtering lenses with traditional short pass wavelength filters (yellow filter - $450 \mathrm{~nm}$ ) a subgroup of 28 patients underwent the same tests with the two different filtering lenses and no filter lenses. Each patient was randomized to one of the 6 possible different testing sequences.

The current study was performed in compliance with the Declaration of Helsinki and international guidelines. Written informed consent was obtained from each participant.

All data were analyzed using linear mixed models that included nested random effects for subject and eye to account for correlation of repeated measures on the same eye (before and after the application of the filtering lenses) and from the same subject (left and right eye). CS and GT data were modeled as a count process with a Poisson error distribution.

\section{Results}

We analyzed data from two sets of patients. The first set was composed of 30 patients with central scotoma: 19 
with Age related Macular Degeneration (AMD), 3 with Stargardt disease, 2 with ocular albinism, 2 with Retinitis Pigmentosa (RP) and single cases of optic nerve atrophy, cone dystrophy, myopic degeneration and diabetic macular edema.

The second set was composed of patients with peripheral scotoma, 29 with RP and 1 with glaucoma. Mean age was $64 \pm 21$ for patients with central scotoma and $49 \pm 13$ for patients with peripheral scotoma. The demographics are summarized in Table 1.

Among patients, all blue-violet filter colors were uniformly represented and no significant association could be detected between the color and the type of scotoma ( $p=0.82$, chi-squared test). Linear mixed models were used to perform multivariate paired tests, with the inclusion of covariates (i.e. the filter color and the location of the scotoma), in order to compare test performances before and after the application of the filtering lenses.

Results are reported in Table 2. Both black on white and white on black visual acuity increased significantly following the application of blue-violet filter lenses. For patients with central scotoma the mean BCVA increased from $0.30 \pm 0.20$ to $0.36 \pm 0.21$ decimals for black on white letters and from $0.31 \pm 0.19$ to $0.38 \pm 0.23$ decimals for white on black (Mean $\pm \mathrm{SD}, p<0.0001$ in both cases). For patients with peripheral scotoma the mean BCVA increased from $0.44 \pm 0.22$ to $0.51 \pm 0.23$ decimals for black on white letters and from $0.46 \pm 0.20$ to $0.56 \pm 0.22$ decimals for white on black (Mean $\pm \mathrm{SD}, p<0.0001$ in both cases).

Significant increases were also detected in CS test: the letter count for the Mars test increased from $26.7 \pm 7.9$ to $30.06 \pm 7.8$ in patients with central scotoma (Mean $\pm \mathrm{SD}, p=0.0005)$ and from $31.5 \pm 7.6$ to $33.72 \pm 7.3$ in patients with peripheral scotoma (Mean \pm SD, $p=0.031$ ).

Glare was also significantly reduced, as shown by the results of the GT: the letter count for increased from $20.93 \pm 5.42$ to $22.82 \pm 4.93$ in patients with central scotoma (Mean $\pm \mathrm{SD}, p<0.0001$ ) and from $24.15 \pm 5.5$ to $25.97 \pm 4.7$ in patients with peripheral scotoma (Mean \pm SD, $p<0.0001$ ).
Interactions between the location of the scotoma and the filter application were used to model the presence of a potentially differential change in patients with peripheral scotoma with respect to those with central scotoma, but in no case we could detect any significantly different behavior between the two groups in terms of performance increase.

Table 2 also reports the mean individual increase (expressed as the average of the subject means of the differences in the test results for the two eyes) in different test performances after the application of blue-violet filtering lenses. Of notice, all test results showed an increased performance in every subject tested except for a reduced white on black BCVA in a single patient with peripheral scotoma.

Table 3 reports the results of the comparison between the effect of blue-violet filter and a standard short pass yellow filter. A subgroup of 28 patients (15 with central scotoma and 13 with peripheral scotoma) was tested as previously described. Significant differences could be detected between the Blue-violet filter and the Yellow filter in all tests, with higher scores recorded with the Blue filter $(p<0.05)$. No significant differences in any test could be detected between the Yellow filter and the No filter condition.

\section{Discussion}

The purpose of our study was to assess potential benefits derived from photocromic and selective blue-violet light filtering spectacle lenses in patients with central or peripheral scotoma.

\section{Short term visual function enhancement}

Results from statistical analysis of our data show that patients wearing photocromic and selective blue-violet light filtering spectacle lenses could improve their visual performances.

In our study, we evaluated two distinct groups of patients: subjects with central scotoma, primarily affected by AMD, and subjects with peripheral scotoma, mostly due to a severe rod dysfunction in RP.

Table 1 Demographic information: for each of the two groups (central or peripheral scotoma) the table reports the male to female ratio in the second column, the mean age in the third column and the distribution of the diseases causing the scotoma within each group

\begin{tabular}{|c|c|c|c|c|}
\hline Demographics Scotoma & M:F & Age (Mean \pm SD) & Disease & \\
\hline Central $(N=30)$ & 12:18 & $64 \pm 21$ & $\begin{array}{l}\text { AMD } \\
\text { Stargardt } \\
\text { Cone Dystrophy } \\
\text { Ocular Albinism } \\
\text { Optic Nerve Atrophy } \\
\text { Degenerative Myopia } \\
\text { Retinitis Pigmentosa } \\
\text { Diabetic CME }\end{array}$ & $\begin{array}{l}19 \\
3 \\
1 \\
2 \\
1 \\
1 \\
2 \\
1\end{array}$ \\
\hline Peripheral $(N=30)$ & 13:17 & $49 \pm 13$ & $\begin{array}{l}\text { Retinitis Pigmentosa } \\
\text { Glaucoma }\end{array}$ & $\begin{array}{l}29 \\
1\end{array}$ \\
\hline
\end{tabular}


Table 2 Reports all test results before (column 3) and after (column 4) the application of filters

\begin{tabular}{|c|c|c|c|c|c|}
\hline \multicolumn{2}{|c|}{ Test results, Mean (SD) } & \multirow{2}{*}{$\begin{array}{l}\text { Without } \\
\text { filters }\end{array}$} & \multirow[t]{2}{*}{ With filters } & \multirow{2}{*}{$\begin{array}{l}\text { Mean Subject } \\
\text { Increase }\end{array}$} & \multirow[t]{2}{*}{$p$} \\
\hline Scotoma & & & & & \\
\hline \multirow[t]{4}{*}{ Central } & BCVA (Black on White) & $0.30(0.20)$ & $0.36(0.21)$ & $0.057(0.03)$ & $<0.0001$ \\
\hline & BCVA (White on Black) & $0.31(0.19)$ & $0.38(0.23)$ & $0.074(0.045)$ & $<0.0001$ \\
\hline & Glare Test & $20.93(5.42)$ & $22.82(4.93)$ & $4.52(1.70)$ & $<0.0001$ \\
\hline & Contrast Sensitivity & $26.7(7.9)$ & $30.06(7.8)$ & $3.37(1.8)$ & 0.0005 \\
\hline \multirow[t]{4}{*}{ Peripheral } & BCVA (Black on White) & $0.44(0.22)$ & $0.51(0.23)$ & $0.074(0.04)$ & $<0.0001$ \\
\hline & BCVA (White on Black) & $0.46(0.2)$ & $0.56(0.22)$ & $0.098(0.064)$ & $<0.0001$ \\
\hline & Glare Test & $24.15(5.5)$ & $25.97(4.7)$ & $3.75(1.3)$ & $<0.0001$ \\
\hline & Contrast Sensitivity & $31.5(7.6)$ & $33.72(7.3)$ & $2.25(1.62)$ & 0.031 \\
\hline
\end{tabular}

Column 5 reports the mean subject increase (expressed as the average of the individual means of the differences in the test results for the two eyes). All results are reported as Mean (SD). The last column reports the significance of each difference obtained from the linear models described in the Method section. Subjects are divided in patients with central scotoma (top white rows) and peripheral scotoma (bottom gray rows)

Despite the differences in the pathophysiological mechanisms of these retinal diseases and consequently in the damage localization within the retinal structures, we could find statistically significant improvements in both groups for each parameter: visual acuity (both black on white and white on black), contrast sensitivity and glare.

Glare is an important factor affecting the quality of life of patients affected by retinal dystrophies. In RP, for example, the RPE becomes inadequate to contrast light intraocular scattering. This, together with progressive death of rods and cones, leads to an increasing difficulty in facing light adaptation to light changes in the environment [18]. Photophobia and consequent glare disability are therefore unavoidable.

In dry AMD, on the other hand, affected patients experience a slow reduction in visual acuity due to macular photoreceptors death and RPE and choriocapillaris degeneration. This leads to the gradual appearance of a central scotoma in the visual field of involved eyes and glare becomes a significant impairment in everyday-life.

Blue-violet light is the interval of visible spectrum carrying the highest energy content and it has been considered the main responsible for glare vision since its discovery.

Technical specifications from Essilor about Transitions XTRActive lenses report a screening effect of the $88-95 \%$ for the outdoor blue-violet light and the $34 \%$ for the indoor radiation [19]. We can thus speculate that our observations may be a consequence of such a filtering property of blue light.

All patients tested, both with central or peripheral scotoma, did not complain about color vision distortion using the blue-violet filter, as opposed to yellow filters. Based the curve of sensitivity of the human eye, it might be hypothesized that such a selectivity for blue-violet light does not alter the colors perception.

Filtering lenses used in our study might have improved both visual acuity and contrast sensitivity by cutting a

Table 3 Reports the Estimated Difference and Standard Errors (SE) obtained by a randomized trial on NN patients

\begin{tabular}{|c|c|c|c|c|}
\hline Test & Comparison & $\begin{array}{l}\text { Estimated } \\
\text { Difference }\end{array}$ & SE & $p$ \\
\hline \multirow[t]{3}{*}{ BCVA (Black on White) } & Blue-violet - Yellow & 0.071 & 0.006 & $<.0001$ \\
\hline & Blue-violet - No Filter & 0.078 & 0.005 & $<.0001$ \\
\hline & Yellow - No Filter & 0.007 & 0.006 & 0.4197 \\
\hline \multirow[t]{3}{*}{ BCVA (White on Black) } & Blue-violet - Yellow & 0.083 & 0.009 & $<.0001$ \\
\hline & Blue-violet - No Filter & 0.088 & 0.008 & $<.0001$ \\
\hline & Yellow - No Filter & 0.004 & 0.009 & 0.8778 \\
\hline \multirow[t]{3}{*}{ Glare Test } & Blue-violet - Yellow & 0.186 & 0.041 & $<.0001$ \\
\hline & Blue-violet - No Filter & 0.204 & 0.041 & $<.0001$ \\
\hline & Yellow - No Filter & 0.018 & 0.043 & 0.9123 \\
\hline \multirow[t]{3}{*}{ Contrast Sensitivity } & Blue-violet - Yellow & 0.089 & 0.036 & 0.0363 \\
\hline & Blue-violet - No Filter & 0.103 & 0.035 & 0.0094 \\
\hline & Yellow - No Filter & 0.014 & 0.037 & 0.9218 \\
\hline
\end{tabular}

Each row block refers to a different test and each row within a block reports all possible differences in the test results between the Blue-violet filter, the Yellow filter and no filter correction. All $p$-values have been calculated with mixed linear models and corrected with the Tukey-Kramer method 
preponderant part of blue-violet glaring radiations, providing more favorable conditions for efficient visual signal coding from the residual photoreceptors.

To the best of our knowledge, no published studies have already explored this topic. Further investigations are needed to better understand the role of selective filtering lenses in improving quality of life in patients affected by different retinal diseases.

\section{Prevention in photoreceptor's loss}

AMD is the most important cause of visual impairment in the elderly population [20] and $d r y-A M D$ accounts for almost the $90 \%$ of the cases [21].

Even though increasing age, genetics and smoking are well established risk factors for AMD [22, 23], it is still not clear whether other aspects, including long-term exposure to short wavelength light, could contribute to the development of the disease [24-27].

This might have significant clinical implications, such as the preference for either blue-light or UVR onlyfiltering intra-ocular lenses in cataract surgery.

The dioptric system of the eye is able to filter UVR light, with the largest contributions from the cornea (for wavelengths below $300 \mathrm{~nm}$ ) and the lens $(300-400 \mathrm{~nm}$ or even larger spectrum intervals when age related opacity is present) $[28,29]$. UVR can induce DNA breakdown and oxidative stress with the production of reactive oxygen species (ROS), which may cause oxidative damage to RPE cells and photoreceptors [30, 31].

Since the discovery of the blue-light hazard, blue light-filtering artificial lenses have been considered as a viable option for retinal protection, although the real impact of this procedure has not been definitely proven.

This might be an option for further protection in patients with retinal diseases undergoing cataract surgery at a young age, such as in RP patients, that would have to renounce the protection offered by their natural crystalline lens.

\section{Conclusions}

Upon these considerations, a wider use of blue-violet light filtering spectacle lenses, especially in RP patients or old people with an increased risk of AMD progression, could not only represent an important instrument to face visual impairment due to retinal pathologies, but could play a complementary role in visual preservation.

Limits of our study are the small sample size and the short follow up time that does not allow observing the safety role of a lower retinal exposure to dangerous radiations by the years.

Well designed, long term studies could unveil which spectrum of visible light is to be filtered according with the human circadian rhythm and what is the real role of blue-violet light in the pathogenesis and the progression of many retinal disease, both degenerative and dystrophic.

\section{Abbreviations}

AMD: Age related Macular Degeneration; BW-BCVA: Black on White Best Corrected Visual Acuity; CS: Contrast Sensitivity; GT: Glare Test; ROS: Reactive Oxygen Species; RP: Retinitis Pigmentosa; WB-BCVA: White on Black Best Corrected Visual Acuity

\section{Acknowledgements}

None

Funding

None

\section{Availability of data and materials}

The datasets used and/or analysed during the current study available from the corresponding author on reasonable request.

\section{Authors' contributions}

LC e PF conceived and coordinated the study, SSA, GS and PF acquired the data, GM, FP and EM analysed and interpreted the data; LC and EM drafted the article; FP helped to draft the manuscript, SDC and LR revised the manuscript critically for important intellectual content. All authors read and approved the final manuscript.

Ethics approval and consent to participate

The study was approved by the internal review boards at the San Paolo Hospital - University of Milan. Written informed consent was obtained from each participant.

Consent for publication

Not applicable

Competing interests

The authors declare that they have no competing interests.

\section{Publisher's Note}

Springer Nature remains neutral with regard to jurisdictional claims in published maps and institutional affiliations.

\section{Author details}

'Department of Ophthalmology, San Paolo Hospital, University of Milan, Milan, Italy. ${ }^{2}$ Department of Ophthalmology, AO Maggiore della Carità, Novara, Italy. ${ }^{3}$ Associazione Retinitis Onlus, San Paolo Hospital, Milan, Italy.

Received: 22 March 2017 Accepted: 13 August 2017

Published online: 22 August 2017

References

1. Noell WK. Retinal damage by light in rats. Invest Ophthalmol. 1966;5(5):450-73.

2. Ham WT. Histological analysis of photochemical lesions produced in rhesus retina by short wave-length light. Invest Ophthalmol Vis Sci. 1978;17:1029-35.

3. Viola $A U$, James LM, Schlangen LJ, Dijk DJ. Blue-enriched white light in the workplace improves self-reported alertness, performance and sleep quality. Scand J Work Environ Health. 2008:34(4):297-306.

4. Kiser AK, Deschler EK, Dagnelie G. Visual function and performance with blue-light blocking filters in age-related macular degeneration. Clin Experiment Ophthalmol. 2008;36(6):514-20.

5. Griswold MS, Stark WS. Scotopic spectral sensitivity of phakic and aphakic observers extending into the near ultraviolet. Vis Res. 1992;32(9):1739-43.

6. Boulton M. Retinal photodamage. J Photochem Photobiol B. 2001;64(2-3):144-61.

7. Crockett RS, Lawwill T. Oxygen dependence of damage by $435 \mathrm{~nm}$ light in cultured retinal epithelium. Curr Eye Res. 1984;3:209-15.

8. Sparrow JR, Nakanishi K, Parish CA. The lipofuscin fluorophore A2E mediates blue light induced damage to retinal pigmented epithelial cells. Invest Ophthalmol Vis Sci. 2000;41:1981-9.

9. Shutt F, Davies S, Kopitz J, Holz FG, Boulton ME. Photodamage to human RPE cells by A2-E. A retinoid component of lipofuscin. Invest Ophthalmol Vis Sci. 2000:41:2303-8.

10. Earnshaw WC, Martins LM, Kaufmann SH. Mammalian caspases: structure, activation, substrates and functions during apoptosis. Annu Rev Biochem. 1999;68:282-424. 
11. Stennicke HR, Salvesen GS. Caspases-controlling intracellular signals by protease zymogen activation. Biochim Biophys Acta. 2000;1477:299-306.

12. Miller DK. Activation of apoptosis and inhibition. Ann N Y Acad Sci. 1999; 886:132-57.

13. Wolf BB, Green DR. Suicidal tendencies: apoptotic cell death by caspase family proteinases. J Biol Chem. 1999;274:20049-52.

14. Salvesen GS, Dixit VM. Caspase activation: the induced-proximity model. Proc Natl Acad Sci U S A. 1999;96:10964-7.

15. Tosini G. Effects of blue light on the circadian system and eye physiology Mol Vis. 2016;22:61-72.

16. Schubert F. Light-Emitting Diodes. Cambridge: Cambridge University Press; 2006; pp. 434.

17. Arnault E. Phototoxic action Spectrum on a retinal pigment epithelium model of age-related macular degeneration exposed to sunlight normalized conditions. Lewin a, ed. PLoS One. 2013;8(8):e71398. doi: 10.1371/journal. pone.0071398

18. Rundquist J. Low vision rehabilitation of retinitis pigmentosa. J Visual Impair Blind. 2004;98:718-24.

19. TRANSITION XTRActive-Technical file, Essilor, France; 2016.

20. Rosenfield PJ. Age-related macular degeneration. In: Yanoff M, Duker JS, Augsburger JJ, eds. Ophthalmology: expert consult. 3rd ed. Philadelphia, PA: Elsevier Mosby (2009); 2016.

21. Buschini E. Age related macular degeneration and drusen: neuroinflammation in the retina. Prog Neurobiol. 2011;95:14-25.

22. Klein RJ. Complement factor $\mathrm{H}$ polymorphism in age-related macular degeneration. Science. 2005:308(5720):358-9.

23. Yang Z. A variant of the HTRA1 gene increases susceptibility to age-related macular degeneration. Science. 2006;314(5801):992-3.

24. Beatty S. Macular pigment and age related macular degeneration. $\mathrm{Br}$. Ophthalmol. 1999;83(7):867-77.

25. Fletcher AE. Sunlight exposure, antioxidants, and age-related macular degeneration. Arch Ophthalmol. 2008;126:1396-403.

26. Taylor HR. The long-term effects of visible light on the eye. Arch Ophthalmol. 1992;110:99-104.

27. Shick T. History of sunlight exposure is a risk factor for age-related macular degeneration. Retina. 2016;36:787-90.

28. Boettner EA. Transmission of the ocular media. Investig Ophthalmol. 1962:1: 776-83.

29. Mellerio J. Yellowing of the human lens: nuclear and cortical contributions. Vis Res. 1987;27:1581-7.

30. Roduit R. MAP kinase pathways in UV-induced apoptosis of retinal pigment epithelium ARPE- 19 cells. Apoptosis. 2008;13:343-53.

31. Tratsk KS. UV irradiation causes multiple cellular changes in cultured human retinal pigment epithelium cells. Graefes Arch Clin Exp Ophthalmol. 2003; 241:852-9.

\section{Submit your next manuscript to BioMed Central and we will help you at every step:}

- We accept pre-submission inquiries

- Our selector tool helps you to find the most relevant journal

- We provide round the clock customer support

- Convenient online submission

- Thorough peer review

- Inclusion in PubMed and all major indexing services

- Maximum visibility for your research

Submit your manuscript at www.biomedcentral.com/submit
Biomed Central 